Sharif University of Technology
Scientia Iranica
Transactions A: Civil Engineering
SCIENTIA
IRAN I CA

Research Note

\title{
Laboratory investigation of geotextile position on CBR of clayey sand soil under freeze-thaw cycle
}

\author{
B. Shams ${ }^{\text {a }}$, A. Ardakani ${ }^{\mathrm{a}, *}$, and M. Roustaei ${ }^{\mathrm{b}}$ \\ a. Faculty of Engineering and Technology, Imam Khomeini International University, Qazvin, Iran. \\ b. Department of Civil Engineering, Islamic Azad University, Qazvin Branch, Qazvin, Iran. \\ Received 25 November 2017; received in revised form 29 May 2018; accepted 10 December 2018
}

\author{
KEYWORDS \\ Geotextile; \\ California bearing \\ ratio; \\ Freeze-thaw cycling; \\ Clayey sand soil; \\ Soil stabilization.
}

\begin{abstract}
Soil in cold regions experiences repetitive freeze-thaw cycles that are considered as one of the most significant phenomena in cold region engineering. Approximately $30 \%$ of soil all around the world and a large portion of fertile lands are exposed to daily or seasonal freeze-thaw cycles. These cycles cause considerable changes in water content, solute movement, permeability, strength parameters, erosion rate, and other physical or chemical characteristics of soil. Nowadays, one of the approaches to improving the physical and mechanical characteristics of the soil is to incorporate geosynthetic material as a layer between the embankment and the ground surface. This paper presents the results of California bearing ratio that tests clayey sandy soil. Moreover, the effect of freezethaw cycles on the compressive strength of geotextile-reinforced soil was investigated. The geotextile layer was placed in five positions at different depths of $1.3,2.6,3.9,5.85$, and $7.8 \mathrm{~cm}$ beneath the surface of the mold and then, the sample was exposed to freeze-thaw cycles. It was found that the optimum depth of the geotextile layer was $3.9 \mathrm{~cm}$. In addition, it could be observed that reinforcing the soil could decrease the weakening effects of freezethaw cycles by up to $41.7 \%$.
\end{abstract}

(C) 2020 Sharif University of Technology. All rights reserved.

\section{Introduction}

Freeze-thaw cycles are a common phenomenon in cold climates that can cause considerable changes in physical or chemical characteristics of soil such as water content, solute movement, permeability, strength parameters, and erosion rate. Approximately $30 \%$ of soil around the world and a large portion of fertile lands are subjected to daily or seasonal freeze-thaw cycles. These cycles usually happen in early spring or

*. Corresponding author. Tel./Fax: +982833901164 E-mail addresses: Behnamshams23@gmail.com (B. Shams); a.ardakani@eng.ikiu.ac.ir (A.Ardakani); mahya_roustaei@yahoo.com ( $M$. Roustaei)

doi: $10.24200 /$ sci. 2019.5461 .1284 late autumn and are more frequent in the upper parts of the gerund due to the frequent severe temperature changes. These cycles could be repeated more than 100 times in some cases. An embankment constructed in a cold region in Canada was damaged by freeze-thaw cycles over a year due to a resulting decrease in loadbearing capacity [1]. Highways which were left without pavement might be damaged by freeze-thaw cycles in few years, as well [2].

Lafleur et al. [3] performed unconfined compression tests on clayey soil in order to evaluate and compare the effects of woven and nonwoven geotextile layers. It was observed that the woven geotextile had less contact productivity than the non-woven geotextile [3]. Yarbasi et al. [4] examined the stabilization effects of silica fume-lime, fly ash-lime, and red mud-cement additive mixtures on two different types of granular 
soil. The results suggested that the samples stabilized with these additive mixtures exhibited higher levels of freezing-thawing durability than unstabilized samples. Moreover, these additive mixtures have been shown to improve the dynamic characteristics of the specimens.

Hazirbaba and Gullu [5] utilized California Bearing Ratio (CBR) tests to evaluate the improving effects of geo-fiber and synthetic fluid additives on the performance of fine-grained soils under freeze-thaw cycles in soaked and unsoaked ones. For soaked samples, it could be observed that adding geo-fibers alone improves the CBR performance, while synthetic fluid treatment results in poor CBR performance. On the contrary, for the unsoaked samples, simultaneous application of synthetic fluid and geo-fibers generally increases the resistance to freeze-thaw cycles. Observations indicated that adding synthetic fluid alone could not be very effective against the detrimental impact of freezethaw cycles for unsoaked samples [5].

A kaolinite clay sample reinforced by polypropylene fibers and steel was exposed to 10 closed-system freeze-thaw cycles by Ghazavi and Roustaie [6]. It was observed that as the number of cycles increased, the unconfined compressive strength of clay samples was reduced by $20-25 \%$. In addition, inclusion of fibers increased the unconfined compressive strength of clay soil samples while decreasing the frost heave. For instance, the addition of $3 \%$ polypropylene fiber could increase the unconfined compressive strength of the soil specimens by $60 \%$ to $160 \%$ before and after the cycles being applied, while the frost heave was reduced by $70 \%$.

The effect of freeze-thaw cycles on strength characteristics of soil specimens reinforced by the geotextile layer was studied by Ghazavi and Roustaie using Unconsolidated Undrained (UU) triaxial compressive tests [7]. A geotextile layer was used to reinforce clayey soil samples at their mid-height. Then, the samples were exposed to up to 9 closed-system cycles. Images of the samples were also taken using Computerized Tomography (CT). It was observed that the undrained triaxial compressive strength of unreinforced specimens was reduced as a result of increasing the number of cycles. Reinforced samples, however, exhibited higher strength values and it was observed that the amount of strength reduction could be reduced from $43 \%$ to $14 \%$ by reinforcing the soil specimens. Using CT images, it was revealed that the free water gradually moved down to the lower parts of the specimens through the voids. Moreover, sample reinforcement was shown to be effective in reducing the changes in the values of cohesion and resilient modulus of the soil affected by freeze-thaw cycles [7].

Utilization of geosynthetic layers reduced the outward horizontal stresses transmitted to the underlying foundation soil from the overlying soil layer on the top. This is known as shear stress reduction effect of geosynthetics. This effect causes an increase in the load-bearing capacity of the foundation soil by inducing general shear rather than a local-shear failure [8-11].

Tom et al. [12] overviewed the influence of geotextile reinforcement on enhancing the strength of pavements. The effects of reinforcement layer position and application of multilayer geotextiles were studied. Soils were collected from three different sites with CBR values of 7.6, 12, and 12.9. Then, CBR tests were performed on subgrade soils with a geotextile layer placed above the surface and at a depth of $4 \mathrm{~cm}$ from the top surface of single and multiple layers. The significant role of geosynthetics in the design and maintenance of modern pavements was emphasized by this study. Moreover, the experimental results indicated that the strength of the subgrade could be increased as a result of geotextile reinforcement, which was shown to be more effective in the soil with the least CBR value. The improvement of the subgrade strength was more significant when the geotextile layer was placed at the top of the subgrade soil, where the CBR value increased from 7.6 to 13.6 for the unreinforced and reinforced soil samples, respectively. The use of multilayer reinforcement was shown to be uneconomical since the increase in the CBR values was not considerable compared to single-layer reinforcement.

Michael and Vinod [13] attempted to investigate the application of different types of coir geotextile materials to reinforcing the subgrade. Reinforced and unreinforced soil samples were subjected to soaked CBR tests. Five different types of geotextiles were used in the study and the effects of placement position and stiffness of the material were examined. Geotextile layers were cut to the size of the mold and were placed in $0.2,0.4,0.6$, and 0.8 ratios of the total depth of it $(12 \mathrm{~cm})$. The results indicated that inclusion of coir geotextiles could have an influencing role in the results of CBR tests. The CBR value of the unreinforced saturated sample was $18.2 \%$, which increased by $18.6 \%$ to $36 \%$ at different placement depths. For different types of geotextile material, the maximum $\mathrm{CBR}$ ratio improvement was observed to be in the range of 1.37 to 1.97, while the smallest values of CBR were obtained when the geotextile layer was placed at 0.2 ratio of the mold's total depth.

\section{Materials}

\subsection{Soil}

In this paper, laboratory tests were applied to clayey sand soil classified as SC in unified soil classification system [14]. Clayey sand soil is an inseparable part of pavements and highly vulnerable to freeze-thaw cycles. Grain size distribution curves are shown in Figure 1. Standard proctor compaction tests were conducted on 


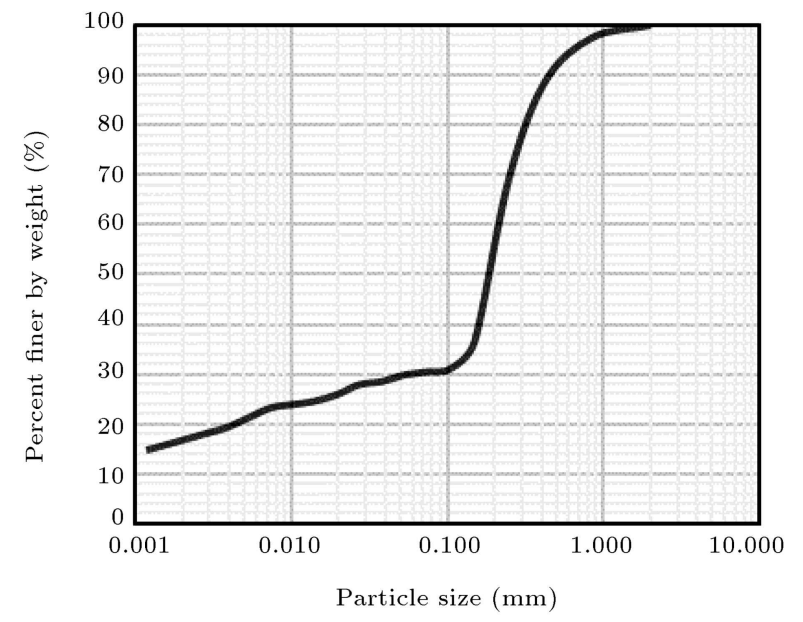

Figure 1. Grain size distribution of the clayey sand soil.

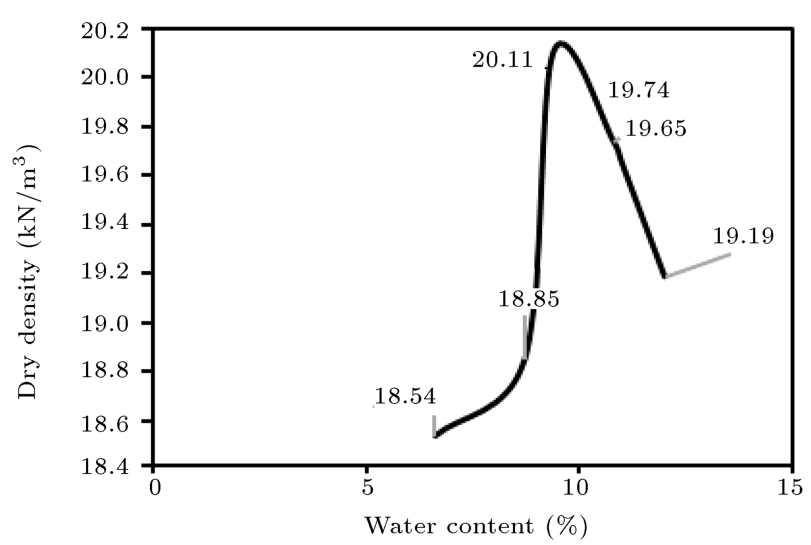

Figure 2. Dry density versus moisture content of clayey sand by modified proctor compaction.

the soil and a maximum dry mass density and optimum moisture of approximately $20.11 \mathrm{kN} / \mathrm{m}^{3}$ and $10 \%$ were obtained, as shown in Figure 2.

\subsection{Geotextile material}

HYTEX-62-nonweven geotextile material was used to reinforce the specimens whose physical and mechanical properties are summarized in Table 1.

\section{Details of the experiments}

The main objective of this research is to investigate the effect of geotextile reinforcement on the CBR values of

Table 1. Physical and mechanical properties of the geotextile material (HYTEX-62-nonweven).

\begin{tabular}{cc}
\hline Geotextile properties & Value (unit) \\
\hline Thickness & $3.3(\mathrm{~mm})$ \\
CBR puncture resistance & $6200(\mathrm{~N})$ \\
Tensile strength & $39(\mathrm{kN} / \mathrm{m})$ \\
Water permeability & $55 \times 10^{-3}(\mathrm{~m} / \mathrm{s})$ \\
Opening size & $70(\mu \mathrm{m})$ \\
\hline
\end{tabular}

highly compressible clayey soil exposed to freeze-thaw cycles. The soil was compacted at the maximum dry density with optimum water content based on standard test method for CBR of laboratory compacted soil [15]. Two freeze-thaw cycles were applied to the specimens according to standard test methods for frost heave and thaw weakening susceptibility of soils [16]. An attempt was made to determine the optimum placement depth of geotextile material.

\subsection{Specimen preparation}

The optimum moisture content, previously determined using the specimen preparation procedure (subsection 2.1 ), was added to the soil. Then, the combination was sealed in two-layer plastic bags for $24 \mathrm{~h}$ in order to keep the moisture content inside the soil specimen uniform. Water content was examined before and after preparation of the specimens [17]. One of the soil samples was compacted without any geotextile layer using the automatic compaction apparatus, while five other samples were prepared by placing one layer of geotextile layers at different depths of 1.3, 2.6, 3.9, 5.85 , and $7.8 \mathrm{~cm}$ beneath the standard CBR mold, as schematically shown in Figure 3 . The abovementioned procedure was repeated for the freeze-thaw tests while the samples were completely sealed using paraffin and plastic layers. During the compaction, the soil container was immediately protected from extra moisture content using a plastic layer. The same action was taken to protect the soil samples after the completion of compaction.

\subsection{CBR test}

$\mathrm{CBR}$ is an easy and economical test used for measuring the bearing capacity of sub-bases and subgrades of road pavements and airfields. The CBR of a soil is defined as the ratio of stress required to cause a standard piston to penetrate $2.54 \mathrm{~mm}$ and $5.08 \mathrm{~mm}$



Figure 3. Placement of geotextile at different depths in California Bearing Ratio (CBR) mold. 
into the soil with maximum dry density to a standard penetration stress at each depth of penetration [15]. In this study, the CBR tests were carried out according to ASTM D, 1883-2007, where the diameter and height of the utilized standard unsoaked molds were $15.2 \mathrm{~cm}$ and $11.7 \mathrm{~cm}$, respectively, and the diameter of the CBR apparatus piston was $5 \mathrm{~cm}$. Modified Proctor compaction energy was used for the CBR samples in accordance with ASTM D 1557-2007. CBR tests were performed under unsoaked conditions. The CBR values reported in this paper present the average of two samples based on Yoder and Witczak research [18].

\subsection{Freeze-thaw cycles}

Freeze-thaw cycles are among the most effective phenomena and can weaken the soil. The present study aims to present useful information about the frost heave potential, thaw weakening, and effect of freezing and thawing cycles on CBR performance. In this study, it is assumed that no external source of water is available during the freezing process; therefore, any change in in-situ water content during summer and winter is negligible. Since freezing of in-situ soils usually occurs from the top and lateral freezing can be neglected [19], one-directional freezing was simulated by applying insulation at the bottom and around the CBR mold. The details of the freeze-thaw setup are schematically presented in Figure 4. Given the existence of external water sources, the freeze-thaw cycles can occur in two systems, i.e., closed and open. Since fine grained soils have low permeability and the traffic loading period is short, a closed system could be a proper choice for modeling the freeze-thaw cycles in these types of soils.

A wide variety of freezing temperatures and durations could be selected based on the type of soil and its location. According to Cook (1963), a majority of deteriorative effects on the strength of compacted soils occur within the first three cycles [20]. In order to investigate the changes in natural freezing conditions, Chamberlain [19] proposed employing at least two freeze-thaw cycles. Lee et al. [21] observed that for simulating the soil effects of freeze-thaw on the resilient characteristics of cohesive soils, one or two freeze-thaw cycles were enough. It should be noted that ASTM D 5918-06 also recommends two freeze-thaw cycles. As an initial cycle, the sample is frozen by holding the temperature constant at $-3^{\circ} \mathrm{C}$ for $8 \mathrm{~h}$. Then, the freezing procedure is applied to the top of the sample by lowering the temperature and holding it constant at $-12^{\circ} \mathrm{C}$ for $16 \mathrm{~h}$. After raising the temperature and holding it at $+12^{\circ} \mathrm{C}$ for $16 \mathrm{~h}$, it is held constant at $3^{\circ} \mathrm{C}$ for another $8 \mathrm{~h}$. The second cycle is the same as the first one. Hence, in this study, two freeze-thaw cycles based on ASTM D 5918-06 were imposed on the compacted soil samples. The soil sample was frozen and thawed by gradually applying specified constant temperatures

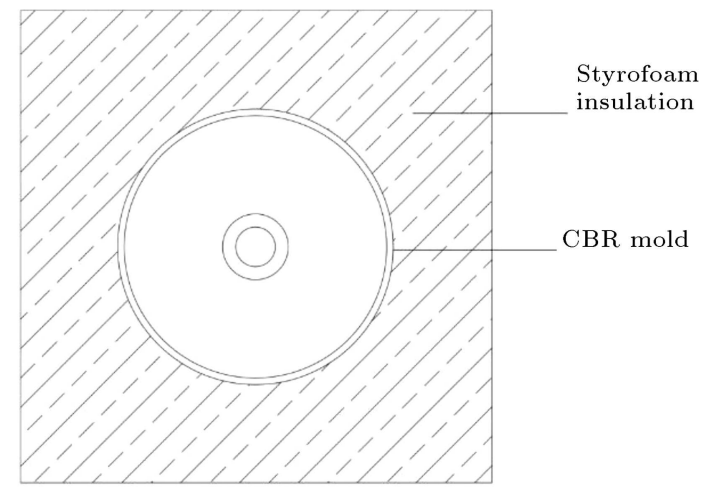

(a)

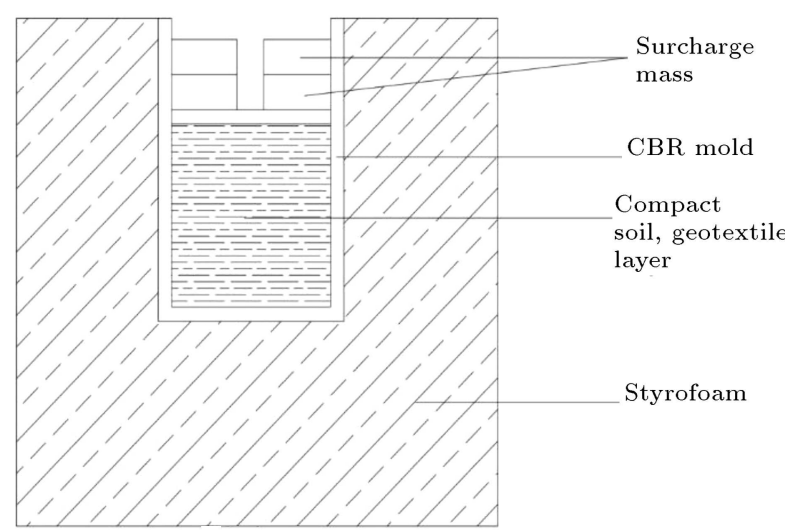

(b)

Figure 4. Schematic of the California Bearing Ratio (CBR) test setup: (a) Plan view of insulated CBR sample and (b) close-up cross-section of an insulated CBR sample.

to the sample, while a surcharge of $3.5 \mathrm{kPa}$ applied to the top. At the end of the second thawing cycle, the bearing ratio was determined. The entire testing procedure was completed within a five-day period. Table 2 presents the temperature setting and timing.

The water content should remain constant during the five-day period of freeze-thaw cycles since small changes in water content may introduce noticeable errors to CBR values. Therefore, the top and bottom parts of the samples were sealed by paraffin and plastic. The water content was examined before compaction and after the CBR tests and compared to the optimum moisture content that has been reported.

\section{Results}

\subsection{Improving effects of geotextile}

The CBR values are commonly reported for standard piston penetrations of $2.54 \mathrm{~mm}$ and $5.08 \mathrm{~mm}$. Generally, geotextile-reinforced soil samples exhibit more strength than unreinforced ones, regardless of the position of the reinforcing layer. Soil has a high compressive strength and a low tensile strength for which the geotextile layer compensates. In the failure 
Table 2. Boundary temperature conditions.

\begin{tabular}{|c|c|c|c|}
\hline Day & Elapsed time (h) & $\begin{array}{c}\text { Top } \\
\text { temperature }\left({ }^{\circ} \mathrm{C}\right)\end{array}$ & Comments \\
\hline 1 & 0 & 3 & $24 \mathrm{~h}$ conditioning \\
\hline \multirow{2}{*}{2} & 24 & -3 & First $8 \mathrm{~h}$ freeze \\
\hline & 32 & -12 & Freeze to bottom \\
\hline \multirow[t]{2}{*}{3} & 48 & 12 & First thaw \\
\hline & 64 & 3 & \\
\hline \multirow[t]{2}{*}{4} & 72 & -3 & Second $8 \mathrm{~h}$ freeze \\
\hline & 80 & -12 & Freeze to bottom \\
\hline \multirow[t]{2}{*}{5} & 96 & 12 & Second thaw \\
\hline & 112 to 120 & 3 & \\
\hline
\end{tabular}

area of the soil, the geotextile layer starts to deform and absorb tensile stresses. The effect of geotextile is reduced as the distance between the failure area and the geotextile layer beneath it increases. The positions of five geotextile layers are at the depths of 1.3, 2.6, 3.9, 5.85 , and $7.8 \mathrm{~cm}$, respectively, beneath the standard CBR mold. Figure 5 shows the pressure values versus penetration of the unreinforced and reinforced samples.

Table 3 presents the CBR values for standard penetration depths of $2.5 \mathrm{~mm}$ and $5 \mathrm{~mm}$ for different geotextile positions. The results indicated that the optimum position of the geotextile layer, for which the highest value of CBR was obtained as $3.9 \mathrm{~cm}$ beneath the standard CBR mold. By moving away from the optimum layer (layer 3 ), the impact of the geotextile layer became less significant. Putting one layer of reinforcement at the $100 \%$ depth of CBR mold was performed without reinforcing the sample [22]. Thus, for the geotextile layer placed at a depth of $7.8 \mathrm{~cm}$ (layer 5), the CBR value was approximately equal to that of the unreinforced sample.

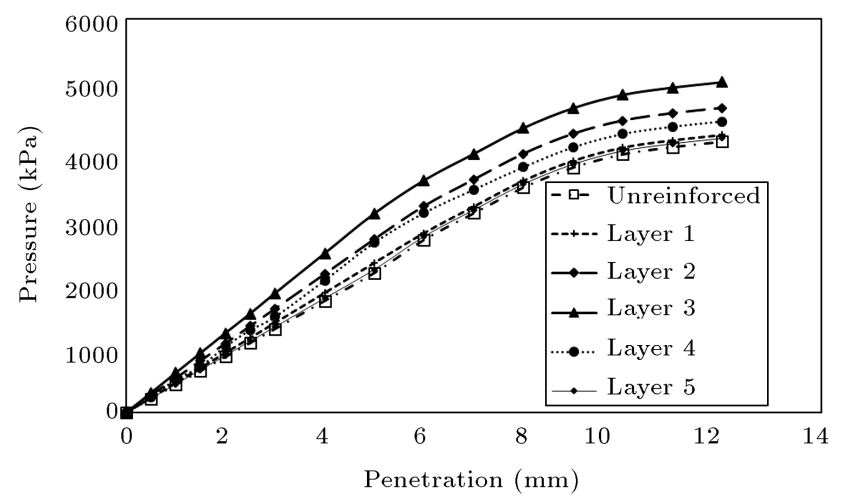

Figure 5. Pressure versus penetration for samples with different geotextile positions.
According to ASTM D 1883-07, when the value of CBR for $5 \mathrm{~mm}$ penetration is higher than that for $2.5 \mathrm{~mm}$, the criterion used for measuring the strength of the soil is the CBR value for $5 \mathrm{~mm}$ penetration [15]. Table 4 shows a comparison in the strength improvement percentages of reinforced and unreinforced soil samples.

Based on the data presented in Table 3, placing the geotextile player at a depth of $3.9 \mathrm{~cm}$ beneath the CBR mold can improve the strength of the sample to a considerable ratio of $42.2 \%$. By comparing the results obtained for Layer 5 with those of other layers, it can be observed that placing the geotextile layer at a depth of $7.8 \mathrm{~cm}$ or more in the standard CBR mold does not result in noticeable improvements. The result of this case is almost the same as that of the unreinforced sample.

\subsection{Freezing and thawing performance}

Freeze-thaw cycles generally have negative effects on the soil strength and deduct the CBR values. Geosynthetics have successfully been used in cold zones to improve the efficiency of roadways [23]. Utilizing geotextile layers can reduce the adverse effects of freezethaw cycles. To examine this finding, samples were subjected to two freeze-thaw cycles according to standard test methods for frost heave and thaw weakening susceptibility of soils [16]. Figure 6 presents the pressure values versus penetration of the unreinforced and reinforced samples under freeze-thaw cycles. The CBR values for the standard penetrations of $2.5 \mathrm{~mm}$ and $5 \mathrm{~mm}$ under freeze-thaw cycles for different geotextile positions are summarized in Table 5 . The results showed that the optimum position of the geotextile layer corresponding to the highest value of CBR was $3.9 \mathrm{~cm}$ beneath the standard CBR mold. 
Table 3. California Bearing Ratio (CBR) values for standard penetrations of $2.5 \mathrm{~mm}$ and $5 \mathrm{~mm}$.

\begin{tabular}{cccc}
\hline $\begin{array}{c}\text { Sample } \\
\text { condition }\end{array}$ & $\begin{array}{c}\text { Depth of geotextile } \\
\text { layer } \mathbf{( c m )}\end{array}$ & $\begin{array}{c}\text { CBR value for } \\
\mathbf{2 . 5} \mathbf{~ m m} \text { penetration }\end{array}$ & $\begin{array}{c}\text { CBR value for } \\
\mathbf{5} \mathbf{~ m m} \text { penetration }\end{array}$ \\
\hline Unreinforced & - & 10.54 & 20.54 \\
& 1.3 (layer 1) & 12.02 & \\
Reinforced & 2.6 (layer 2) & 14 & 22.2 \\
& 3.9 (layer 3) & 15.7 & 25.5 \\
& 5.85 (layer 4) & 13 & 29.25 \\
& 7.8 (layer 5) & 11.3 & 25.4 \\
\hline
\end{tabular}

Table 4. Improvements of the soil strength.

\begin{tabular}{ccc}
\hline Sample condition & $\begin{array}{c}\text { Depth of geotextile } \\
\text { layer }(\mathbf{c m})\end{array}$ & $\begin{array}{c}\text { CBR value for 5 } \mathbf{~ m m} \\
\text { penetration }\end{array}$ \\
\hline Unreinforced & - & - \\
& 1.3 (layer 1) & $8.08 \%$ \\
Reinforced & 2.6 (layer 2) & $24.14 \%$ \\
& 3.9 (layer 3) & $42.4 \%$ \\
& 5.85 (layer 4) & $23.6 \%$ \\
& 7.8 (layer 5) & $2.3 \%$ \\
\hline
\end{tabular}

Table 5. California Bearing Ratio (CBR) values for standard penetration of $2.5 \mathrm{~mm}$ and $5 \mathrm{~mm}$ under freeze-thaw cycles.

\begin{tabular}{cccc}
\hline $\begin{array}{c}\text { Sample } \\
\text { condition }\end{array}$ & $\begin{array}{c}\text { Depth of geotextile } \\
\text { layer } \mathbf{( c m )}\end{array}$ & $\begin{array}{c}\text { CBR value for } \\
\mathbf{2 . 5} \mathbf{~ m m} \text { penetration }\end{array}$ & $\begin{array}{c}\text { CBR value for } \\
\mathbf{5 m} \text { }\end{array}$ \\
\hline Unreinforced & - & 4.17 & 7.88 \\
& $1.3($ layer 1) & & \\
Reinforced & $2.6($ layer 2) & 4.29 & 8.46 \\
& 3.9 (layer 3) & 4.9 & 9.86 \\
& $5.85($ layer 4) & 5.64 & 11.17 \\
& $7.8($ layer 5) & 4.41 & 8.71 \\
& & 4.17 & 7.88 \\
\hline
\end{tabular}

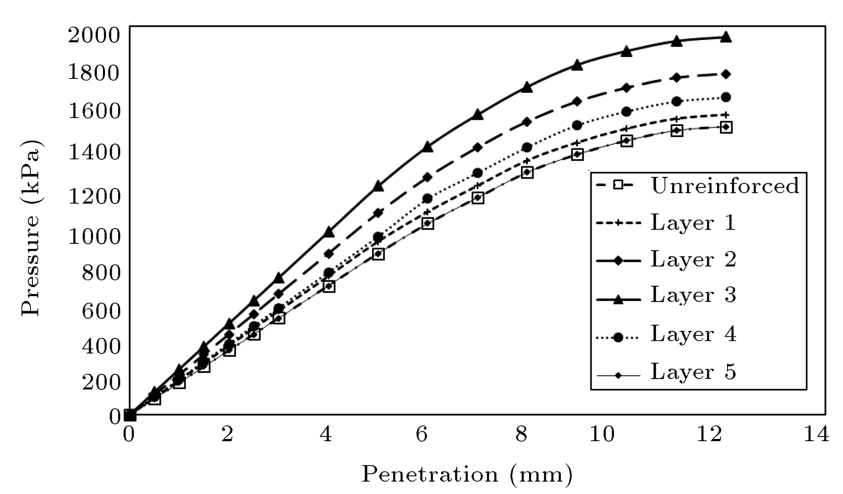

Figure 6. Pressure versus penetration for samples with different geotextile positions under two freeze-thaw cycles according to ASTM D 5918-06.

Table 6 shows the comparison in the improvement percentages of the strengths of reinforced soil samples and unreinforced sample under the freeze-thaw cycles.
It can be concluded from Table 6 that under the freezethaw cycles, positioning the geotextile layer at a depth of $3.9 \mathrm{~cm}$ beneath the CBR mold can improve the strength of the sample by a significant ratio of $41.7 \%$, compared to the unreinforced sample.

To justify the reasons why the CBR samples are large among the other soil samples, two temperature sensors were set inside the soil samples in order to ensure the temperature adaptation between the freezer and inside the sample. Figure 7 shows the temperature of freezer and inside the CBR sample during the first freeze-thaw cycle. With respect to this figure, it can be suggested that although the temperature variation of the soil sample is lower than the changes in freezer temperature, after about four hours from the cycle beginning, the temperature of the central part of the sample reaches a freezer temperature.

Figure 8 shows the CBR values with and without 
Table 6. Improvements of the soil strength under the freeze-thaw cycles.

\begin{tabular}{ccc}
\hline $\begin{array}{c}\text { Sample } \\
\text { condition }\end{array}$ & $\begin{array}{c}\text { Depth of geotextile } \\
\text { layer } \mathbf{( c m )}\end{array}$ & $\begin{array}{c}\text { CBR value for } \\
\mathbf{5 ~} \mathbf{~ m m} \text { penetration }\end{array}$ \\
\hline Unreinforced & - & - \\
& 1.3 (layer 1) & $7.3 \%$ \\
Reinforced & 2.6 (layer 2) & $25 \%$ \\
& 3.9 (layer 3) & $41.7 \%$ \\
& 5.85 (layer 4) & $10.5 \%$ \\
& 7.8 (layer 5) & $0 \%$ \\
\hline
\end{tabular}

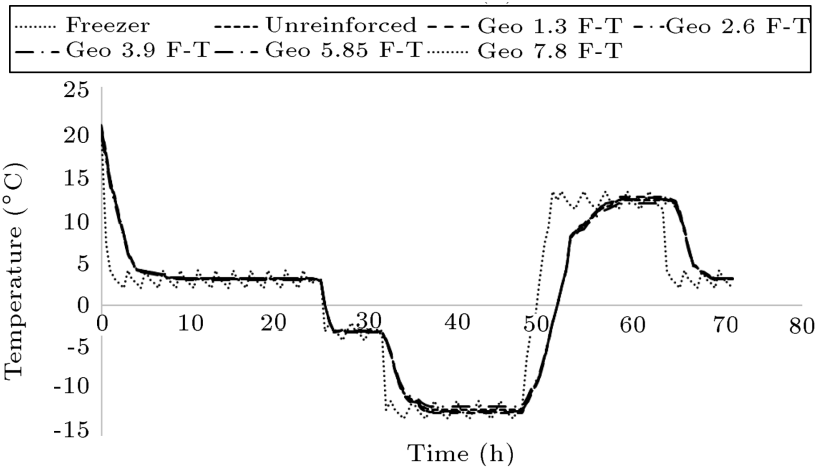

Figure 7. Temperatures of freezer and reinforced California Bearing Ratio (CBR) samples in a cycle.

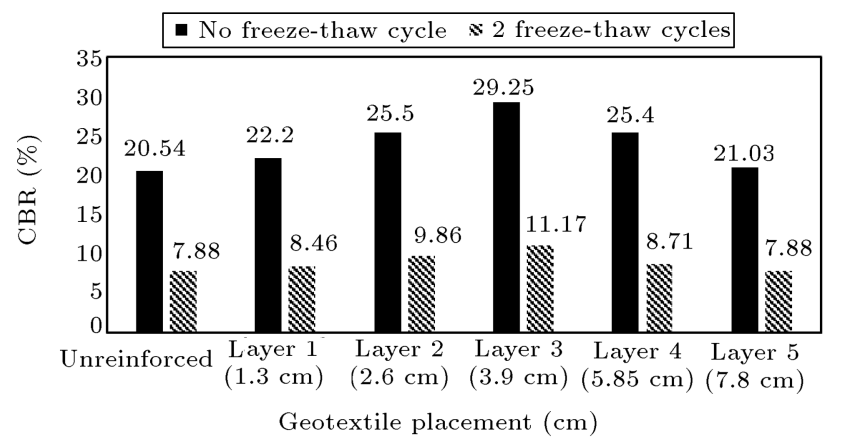

Figure 8. Comparison of the California Bearing Ratio (CBR) values for the unreinforced and reinforced soil samples with and without freeze-thaw cycles.

freeze-thaw cycles. It can be observed that in both conditions, using geotextile layer has an improving effect on the CBR values of the soil samples. CBR value for the unreinforced sample was reduced to about $61.6 \%$ under the effect of freeze-thaw cycles and placing a geotextile layer at the optimum depth (layer 3) could reduce the effect of freeze-thaw up to $16 \%$. For the non-optimal depths of geotextile layer, increasing the placement depth layer reduced the CBR values.

The alterations in mechanical characteristics of the specimens result from the alterations in their physical conditions during the freeze-thaw cycles. As seen in Table 1, given the permeability of the geotextile layer, water is allowed to pass through freely. Ice crystals formed during the freezing phase start to melt during the thawing phase; therefore, free water could be seen in the specimen. Gravity force makes this free water move down in the specimen and the process is facilitated by the permeability of the geotextile layer. By measuring water contents in different parts of the reinforced samples after exposure to freeze-thaw cycles, the above phenomenon can be confirmed. As anticipated, the lower parts of the specimen exhibited higher water content values than the upper parts. Nonetheless, the difference is more significant for the reinforced samples since the geotextile layer drains water from the upper parts of the specimen. Therefore, as the number of cycles and the number of enlarged pores left after the thawing phase increased, the strength of the soil decreased. This can explain the improving effect of reinforcement on the strength reduction of the soil samples since lower water content results in considerable resistance of the upper part of the soil sample.

\section{Conclusions}

In this paper, an experimental study was carried out in order to investigate the improving effects of geotextile layers in different positions on the California Bearing Ratio (CBR) strength and freeze-thaw performance of a clayey sand soil. The main conclusions of this study can be summarized as follows:

- Existence of a single layer of geotextile in the soil generally results in an increase in the load-bearing capacity and CBR value of the soil;

- Upon increasing the penetration depth of the standard CBR piston in the soil, the CBR values increasd due to more geotextile deformation and higher tensile stress absorption through the soil;

- For the clayey sand soil tested in this study, the optimum geotextile position was approximately at a depth of $3.9 \mathrm{~cm}$ beneath the standard CBR mold. By placing a single layer of geotextile at a depth of 3.9 , the CBR value can be increased by up to $42.2 \%$ in comparison to the unreinforced specimen; 
- By taking distance from the optimum placement depth of the geotextile layer, the improvement decreased. According to findings, at a depth of $7.8 \mathrm{~cm}$, the CBR values for the reinforced and unreinforced samples were practically the same. This can be result of low radius effect;

- Freeze-thaw cycles decrease the CBR values in both reinforced and unreinforced samples by about $61-$ $66 \%$. This phenomenon can be due to drainage function of the geotextile layer which drains water from the upper parts of the specimen. Therefore, as the number of cycles and the number of enlarged pores left after the thawing phase increased, the strength of the soil sample was reduced;

- Existence of a non-woven geotextile layer could reduce the effects of freeze-thaw cycles. The most significant improving effect of geotextile reinforcement was to decrease the reducing effect of freezethaw cycles from $61.6 \%$ to $45.6 \%$ by placing the geotextile layer at the optimum depth. Comparison of the results of the unreinforced and reinforced samples indicated that placing the geotextile layer at the optimum depth could increase the CBR value by about $41.7 \%$.

Based on the observations of this study, utilization of geotextile layers in cold regions, where shallower soil layers can be subject to freeze-thaw cycles, is generally recommended. Using geotextile layers increases the peak strength of the soil while decreasing the negative effects of freeze-thaw cycles. This can generally result in the significant reduction of maintenance costs of the buildings and pavements.

\section{References}

1. Leroueil, S., Tardif, J., Roy, M., Rochelle, P.L., and Konrad, J.M. "Effects of frost on the mechanical behaviour of Champlain Sea clays", Can. Geotech. J., 28(5), pp. 690-697 (1991).

2. Eigenbrod, K.D. "Effects of cyclic freezing and thawing on volume changes and permeabilities of soft finegained soils", Can. Geotech. J., 33(4), pp. 529-537 (1996).

3. Lafleur, J., Sall, M.S., and Ducharme, A. "Frictional characteristics of geotextiles with compacted lateritic gravels and clays", Geosynth. New Orleans, 87(1), pp. 205-215 (1987).

4. Yarbasi, N., Kalkan, E., and Akbulut, S. "Modification of the geotechnical properties, as influenced by freezethaw, of granular soils with waste additives", Cold. Reg. Sci. Technol., 48(1), pp. 44-54 (2007).

5. Hazirbaba, K. and Gullu, H. "California bearing ratio improvement and freeze-thaw performance of finegrained soils treated with geofiber and synthetic fluid MM", Cold. Reg. Sci. Technol., 63(1), pp. 50-60 (2010).
6. Ghazavi, M. and Roustaie, M. "The influence of freezethaw cycles on the unconfined compressive strength of fiber-reinforced clay", Cold. Reg. Sci. Technol., 61(2), pp. 125-131 (2010).

7. Ghazavi, M. and Roustaei, M. "Freeze-thaw performance of clayey soil reinforced with geotextile layer", Cold. Reg. Sci. Technol., 89, pp. 22-29 (2013).

8. Guido, V.A., Chang, D.K., and Sweeney, M.A. "Comparison of geogrid and geotextile reinforced earth slabs", Can. Geotech. J., 23(4), pp. 435-440 (1986).

9. Espinoza, R.D. "Soil-geotextile interaction: evaluation of membrane support", Geotext and Geomembranes., 13(5), pp. 281-293 (1994).

10. Espinoza, R.D. and Bray, J.D. "An integrated approach to evaluating single-layer reinforced soils", Geosynth. Int., 2(4), pp. 723-739 (1995).

11. Adams, M.T. and Collin, J.G. "Large model spread footing load tests on geosynthetic reinforced soil", Foundations. J. Geotech. Geoenviron. Eng., 123(1), pp. 66-72 (1997).

12. Tom, A.F., Abraham, A., and Chacko, A. "Influence of position of geosynthetic layer in pavement", Int. $J$. Eng.Res. Dev., 6(4), pp. 74-78 (2013).

13. Michael, M. and Vinod, P. "California bearing ratio of coir geotextile reinforced subgrade", 10th National Conference on Technological Trends (NCTT09), 6-7, pp. 63-67 (2009).

14. ASTM D422-63, Standard Test Method for ParticleSize Analysis of Soils, West Conshohocken, PA, United States (2007).

15. ASTM D 1883, Standard Test Method for CBR (California Bearing Ratio) of Laboratory-Compacted Soil, West Conshohocken, PA, United States (2007).

16. ASTM D 5918, Standard Test Methods for Frost Heave and Thaw Weakening Susceptibility of Soils, West Conshohocken, PA, United States (2006).

17. Roustaei, M., Ghazavi, M., and Aliaghaei, E. "Application of tire crumbs on mechanical properties of a clayey soil subjected to freeze-thaw cycles", Scientia Iranica, Transactions A, Civil Engineering, 23(1), pp. 122-132 (2016).

18. Yoder, E.J. and Witczak, M.W., Principles of Pavement Design, Wiley, New York (1975).

19. Chamberlain, E.J. "Frost susceptibility of soil: review of index tests", Monograph 81-2. U.S. Army Cold. Reg. Res. Eng. Lab., New Hampshire (1981).

20. Cook, R.D. "Some effects of closed system freezethaw cycles on a compacted, highly plastic clay", $\mathrm{PhD}$ Dissertation, University of Alberta (1963).

21. Lee, W., Bohra, N.C., Altschaeffl, A.G., and White, T.D. "Resilient modulus of cohesive soils and the effect of freeze-thaw", Can. Geotech. J., 32(4), pp. 559-568 (1995).

22. Ahmed Kamel, M., Chandra, S., and Kumar, P. "Behavior of subgrade soil reinforced with geogrid", Int. J. of Pavement. Eng., 5(4), pp. 201-209 (2004). 
23. Han, J. and Jiang, Y. "Use of geosynthetics for performance enhancement of earth structures in cold regions", Sciences in Cold and Arid Regions, 5(5), pp. $517-529$ (2013).

\section{Biographies}

Behnam Shams received his MSc degree in Geotechnical Engineering in 2016 from International Imam Khomeini University of Qazvin. His research interests include soil improvement and soil reinforcement.

Alireza Ardakani was born in Iran, 1984. He received the $\mathrm{PhD}$ degree (with honors) in Geotechnical Engineering from Tarbiat Modares University in 2012. He is currently an Assistant Professor at Faculty of
Technical and Engineering of Imam Khomeini International University. His research interests include soil improvement, soil reinforcement, numerical modeling, and application of artificial intelligence in geotechnical engineering.

Mahya Roustaei received her BSc degree in Civil Engineering from University of Science and Culture, Tehran in 2006 and MSc and PhD degrees in Geotechnical Engineering in 2008 and 2013 from Khaje Nasir Toosi University of Technology (K.N.T.U), respectively. In 2010, she joined the Department of Civil at Qazvin Branch of Islamic Azad University, QIAU, where she is currently an Assistant Professor. She has also been selected as the Director of Construction and Concrete Research Center (CCRC) of QIAU in 2014. 